\title{
Distribution of glutathione $S$-transferase isoenzymes in human ovary
}

\author{
M. Rahilly, P. J. Carder, A. Al Nafussi and D. J. Harrison \\ Department of Pathology, University of Edinburgh Medical School, Teviot Place, \\ Edinburgh, EH8 9AG, UK
}

\begin{abstract}
Summary. Glutathione $S$-transferases (GST) are drug-metabolizing and detoxification enzymes involved in the intracellular transport and metabolism of steroid hormones. We studied expression of $\pi, \alpha, \mu$ and microsomal GST by immunohistochemistry in normal human ovaries at different stages of the menstrual cycle and pregnancy and after the menopause. Antibodies were raised in rabbits to purified GST subunits and formalin-fixed, paraffin-embedded sections were studied using the peroxidaseantiperoxidase method. Staining density was graded from very strong to negative. All four isoenzymes were identified in the ovary and their distribution was heterogeneous. The staining pattern of follicles varied with the stage of the menstrual cycle for each isoenzyme. All the ovaries contained abundant GST $\pi$ in stroma. GST $\alpha$ is closely associated with the glutathione-dependent enzyme $\delta$-5,3-ketosteroid isomerase, which catalyses the conversion of pregnenolone to progesterone and dehydroepiandrosterone to androstenedione. GST $\alpha$ was localized to the steroid-producing cells and thus may be useful in studying ovaries in conditions where there are assumed alterations in steroid production.
\end{abstract}

Keywords: glutathione $S$-transferase; immunohistochemistry; ovarian function; steroidogenesis

\section{Introduction}

The glutathione $S$-transferases (GST) are multifunctional proteins present in many organs (Jakoby, 1978) and show tissue-specific expression (Pabst et al., 1983; Mannervik, 1985). They have the capacity to detoxify electrophilic xenobiotics, including cytotoxic drugs and carcinogens by catalysing their conjugation with reduced glutathione (Jakoby, 1978; Pabst et al., 1983; Mannervik, 1985). The biological functions and endogenous substrates of GSTs are unclear (Mannervik, 1985), but GSTs are known to bind corticosteroids and steroid hormone metabolites and may play an important role in the intracellular transport of these substances (Kamisaka et al., 1975; Listowsky et al., 1988).

Multiple forms of GSTs originate from dimeric combination of different subunits (Habig et al., 1974; Hayes \& Mantle, 1986). There are three distinct homodimeric or heterodimeric classes of cytosolic GST ( $\pi, \alpha$ and $\mu$ ) in man (Hayes et al., 1987) and one trimeric, membrane-bound form known as microsomal GST (Morgenstern \& De Pierre, 1986). GST $\mu$ exhibits genetic polymorphism and, in $40 \%$ of the population, is not expressed in liver (Hussey et al., 1987). Sherman et al. (1983) identified GST $\pi$ as the major isoenzyme in human ovary. However, the ovary is composed of several structures with differing metabolic characteristics. This study examined GST isoenzyme distribution by immunohistochemical analysis in ovaries before and after the menopause. Isoenzyme localization was evaluated with regard to steroidogenic activity at these sites. 


\section{Materials and Methods}

Tissue. Twenty histologically normal ovaries were examined: 11 from women of reproductive age with normal menstrual cycles; 2 from women with tubal pregnancies, both of whom had subserosal focal decidualization; and 7 from postmenopausal women. Formalin-fixed, paraffin-embedded tissue blocks and sections stained with haematoxylin and eosin were available in each case, with a clinical history. The premenopausal women were all under 45 years of age. Each case was reassessed by two pathologists. The status of each ovary in respect to the stage of the menstrual cycle was calculated by dating the endometrium and, in the postovulatory cases, by the morphology of the corpus luteum.

Antibodies to GST. Polyclonal antisera to GST isoenzymes were used. The preparation of GST antisera from purified human isoenzymes, rabbit immunization schedule and assessment have been described previously (Hayes \& Mantle, 1986; Hayes et al., 1987). These antisera reacted specifically with GST $\pi, \alpha$ and $\mu$ and microsomal GST. There was no cross-reactivity on Western blots.

Immunostaining. Immunohistochemistry was performed using a standard avidin-biotin-peroxidase method, as previously described (Hayes et al., 1989). Sections were cut at $3 \mu \mathrm{m}$, dewaxed and incubated with rabbit antiGST for $1 \mathrm{~h}$ at room temperature and then diluted 1:200 in phosphate-buffered saline at $\mathrm{pH} 7 \cdot 4$. After washing, antibody binding was detected using biotinylated goat antirabbit immunoglobulin $G$ (Dako, UK) and an avidin-peroxidase complex (Dako, UK). Visualization was achieved using 3,3-diaminobenzidine as substrate. Slides were lightly counterstained with haematoxylin. The primary antibody was omitted in negative controls and sections of normal liver were used as positive controls.

\section{Results}

Of the 11 ovaries from premenopausal women, 6 were pre-ovulatory and 5 were from 1 to 13 days after ovulation. All those from postmenopausal women had inactive endometrium on microscopic examination. All four GST isoenzymes were identified, although the pattern of staining differed (Table 1).

Table 1. Distribution of glutathione $S$-transferase isoenzymes in normal human ovaries

\begin{tabular}{|c|c|c|c|c|}
\hline \multirow[b]{2}{*}{ Site of activity } & \multicolumn{4}{|c|}{ Isoenzymes } \\
\hline & $\pi$ & $\alpha$ & $\mu$ & Microsomal \\
\hline $\begin{array}{l}\text { Germinal epithelium and } \\
\text { germinal inclusion cysts }\end{array}$ & 0 to \pm & 0 & 0 & 0 \\
\hline Stroma & & & & \\
\hline Cortex & ++ & focal nests +++ & \pm to + & 0 \\
\hline Medulla & + & focal nests +++ & \pm & 0 \\
\hline Decidual cells & ++ & ++ & ++ & ++ \\
\hline Ova & + & 0 & \pm & \pm \\
\hline Granulosa cells & + & \pm & 0 & 0 \\
\hline Granulosa lutein cells & + & + & \pm & + \\
\hline Theca interna cells & \pm to + & $t+t$ & $\overline{0}$ & 0 \\
\hline Theca lutein cells & 0 & +++ & 0 & 0 \\
\hline Theca externa & + & 0 & 0 & 0 \\
\hline Hilus cells & + & +++ & \pm & \pm \\
\hline Rete ovarii & + & $+t$ & 0 & 0 \\
\hline Vascular smooth muscle & 0 to \pm & 0 & + & 0 \\
\hline Vascular endothelium & 0 & 0 & 0 & + \\
\hline
\end{tabular}

Density of staining: +++ very strong, ++ strong, + positive, \pm weak and 0 negative.

\section{GST $\pi$}

This showed predominantly cytoplasmic localization. Abundant GST $\pi$ was uniformly expressed in the stroma, particularly the cortex (Fig. 1). Staining intensity in the granulosa cells increased as 
they developed from the follicular epithelial cells of the primordial follicle into the granulosa lutein cells of the mature corpus luteum, and diminished as this structure regressed (Figs 1-3). Theca interna cells showed variable cytoplasmic staining in Graafian follicles and corpora lutea.
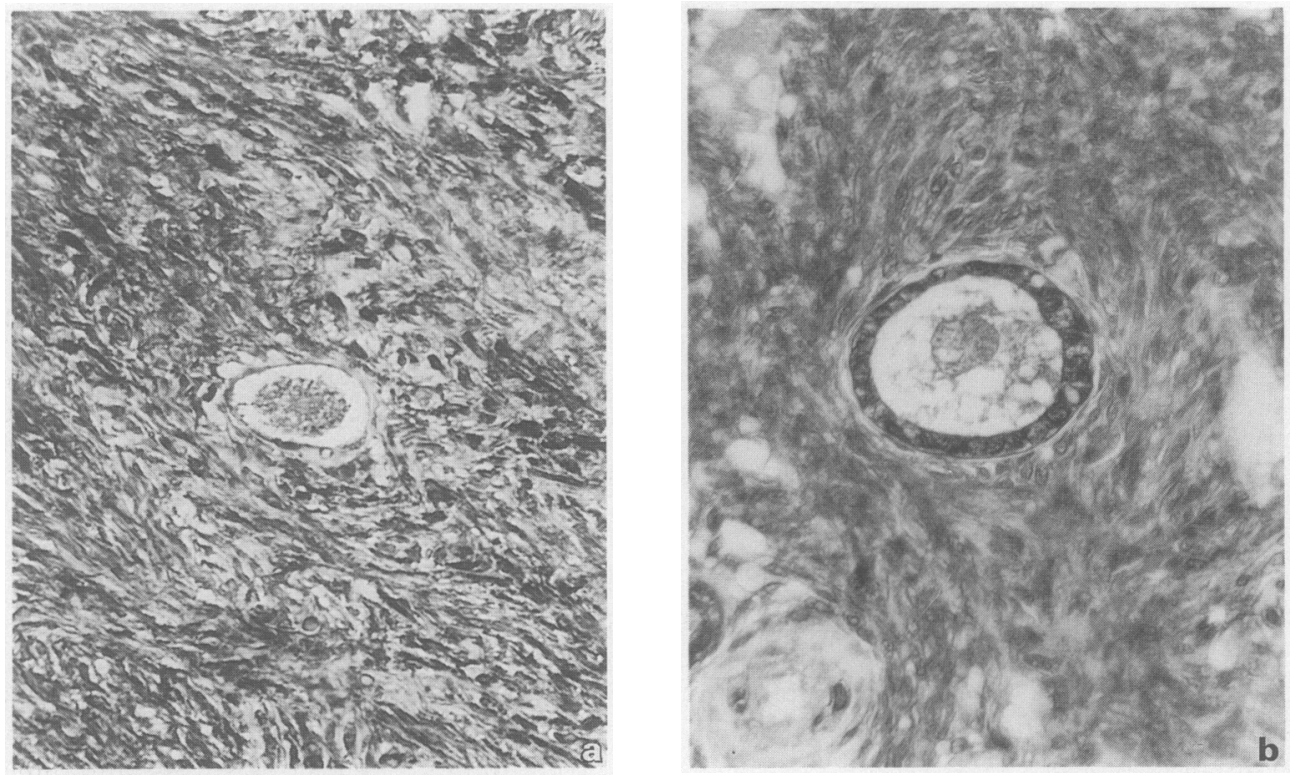

Fig. 1. (a) Primordial follicle within human ovarian cortex. Note strong uniform staining of stroma for glutathione $S$-transferase $\pi(\times 320)$. (b) Human primary follicle showing positive staining of follicular epithelium for glutathione- $S$-transferase $\pi(\times 320)$.

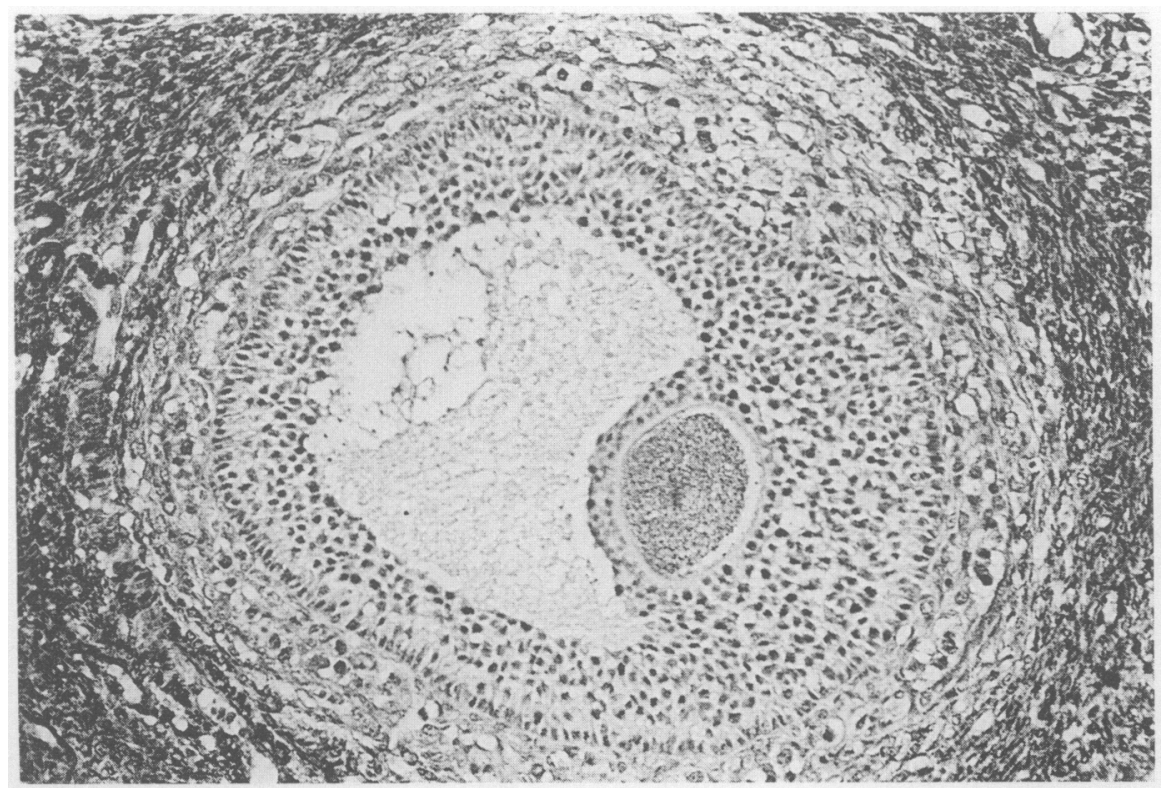

Fig. 2. Human Graafian follicle with the granulosa cell layer staining positively for glutathione $S$-transferase $\pi$. Occasional theca interna cells show weak positivity $(\times 160)$. 


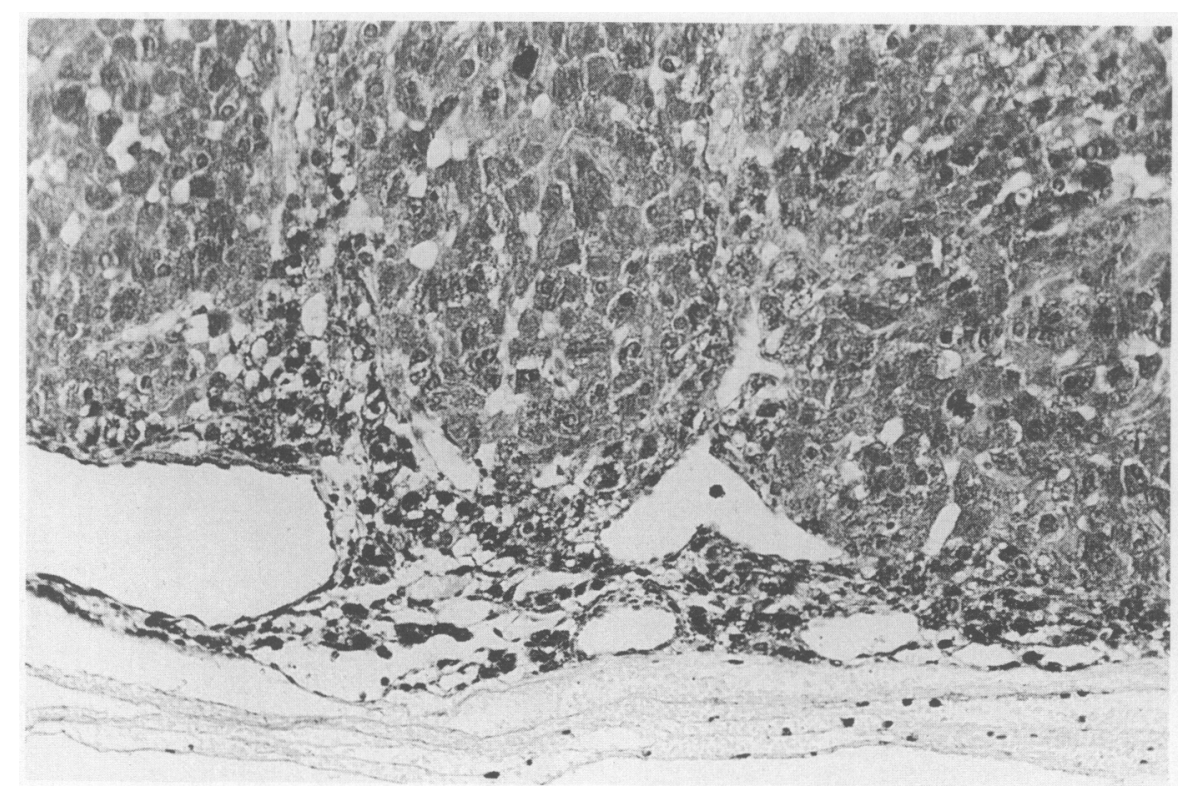

Fig. 3. Mature human corpus luteum of menstruation showing uniform granular cytoplasmic staining for glutathione $S$-transferase $\pi$ in granulosa lutein cells $(\times 160)$.

\section{GSTa}

This isoenzyme displayed a characteristic staining pattern, with both nuclear and cytoplasmic localization. Compact nests of stromal cells showed intense positivity in 5 of 13 ovaries from premenopausal women and in 6 of 7 ovaries from postmenopausal women. These nests were more numerous in the medullary region of the ovary. Comparison with routine histological preparations showed that some positive cells were luteinized stromal cells, but the majority corresponded with whorled, spindle-shaped stromal cells indistinguishable from adjacent nonreactive stromal cells (Fig. 4). Their morphology and distribution were consistent with so-called enzymatically active stromal cells (EASC). Striking positivity was observed in theca interna cells of antral, Graafian and atretic follicles; mature and degenerating corpora lutea; hilus cell aggregates; and the cells of rete ovarii (Figs 5, 6 and 7). Conversely, granulosa cells of primordial, primary and atretic follicles were negative, whereas Graafian follicles and all corpora lutea showed variable cytoplasmic positivity in the granulosa cell layer.

\section{GST $\mu$}

Seven of 20 ovaries (35\%) did not express any detectable GST $\mu$, the rest showed a stromal staining pattern similar to that of GST $\pi$. Pre-ovulatory follicles were uniformly negative, but granulosa lutein cells showed weak cytoplasmic positivity (Fig. 8). The nodular decidua found in 2 ovaries showed strong cytoplasmic positivity. GST $\mu$ was also present in vascular smooth muscle and smooth muscle of the ovarian hilum.

\section{Microsomal GST}

In 14 of 20 ovaries $(70 \%)$ there was no detectable expression of microsomal GST. The stromal components were negative in 4 of the remaining 6 ovaries. Both ovaries from the ectopic pregnancies showed strong cytoplasmic positivity in decidualized stromal nodules (Fig. 9a, b). No microsomal 


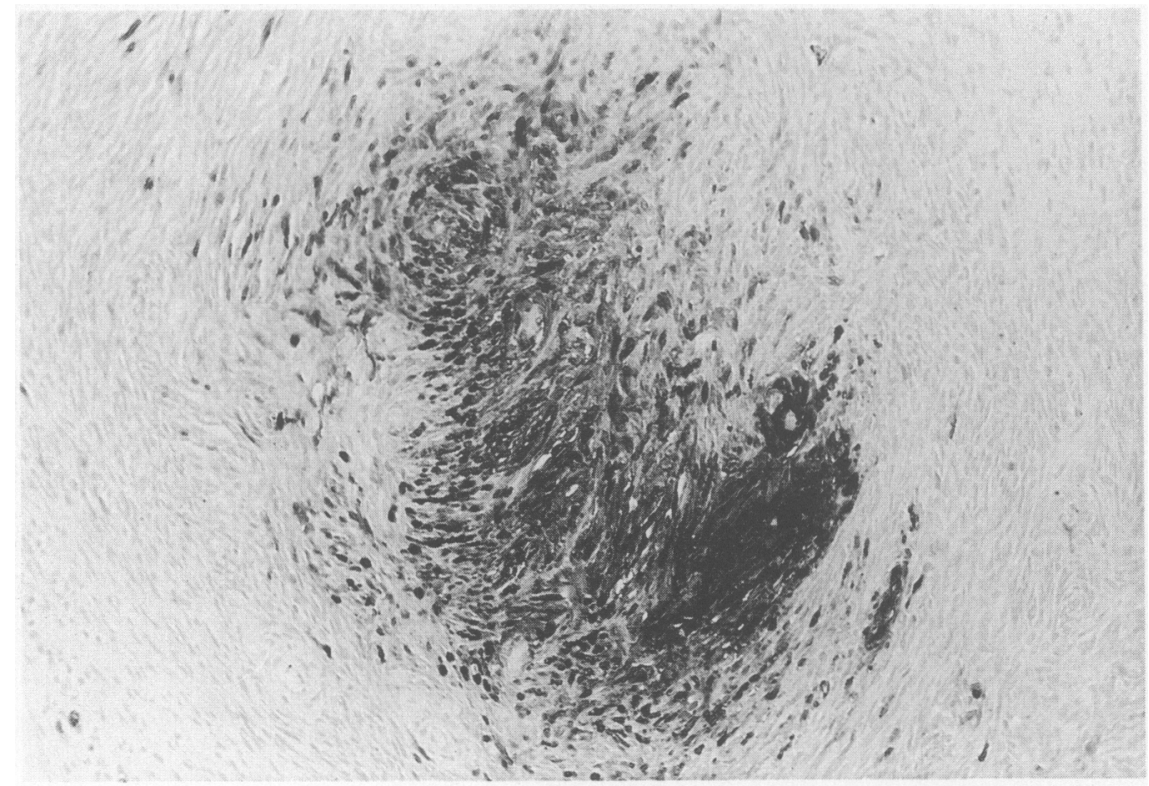

Fig. 4. Strong staining for glutathione $S$-transferase $\alpha$ in a nest of enzymatically active stromal cells in human ovary. Note the lack of staining in adjacent medullary stroma $(\times 160)$.

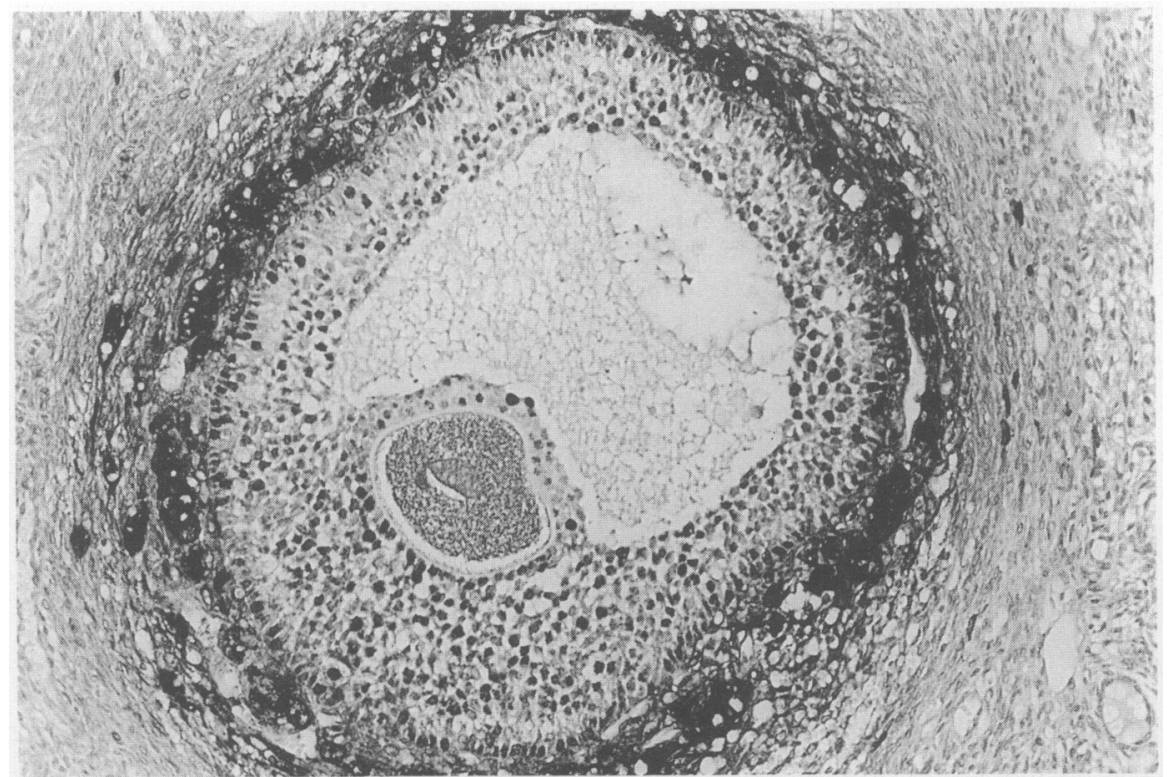

Fig. 5. Human Graafian follicle showing intense staining for glutathione $S$-transferase $\alpha$ in the theca interna and lesser activity in granulosa cells $(\times 160)$.

GST was identified in pre-ovulatory follicles but the corpora lutea showed patchy cytoplasmic positivity of granulosa lutein cells. Hilum cells showed weak reactivity. Microsomal GST was expressed strongly in the vascular endothelium of the 6 ovaries. 

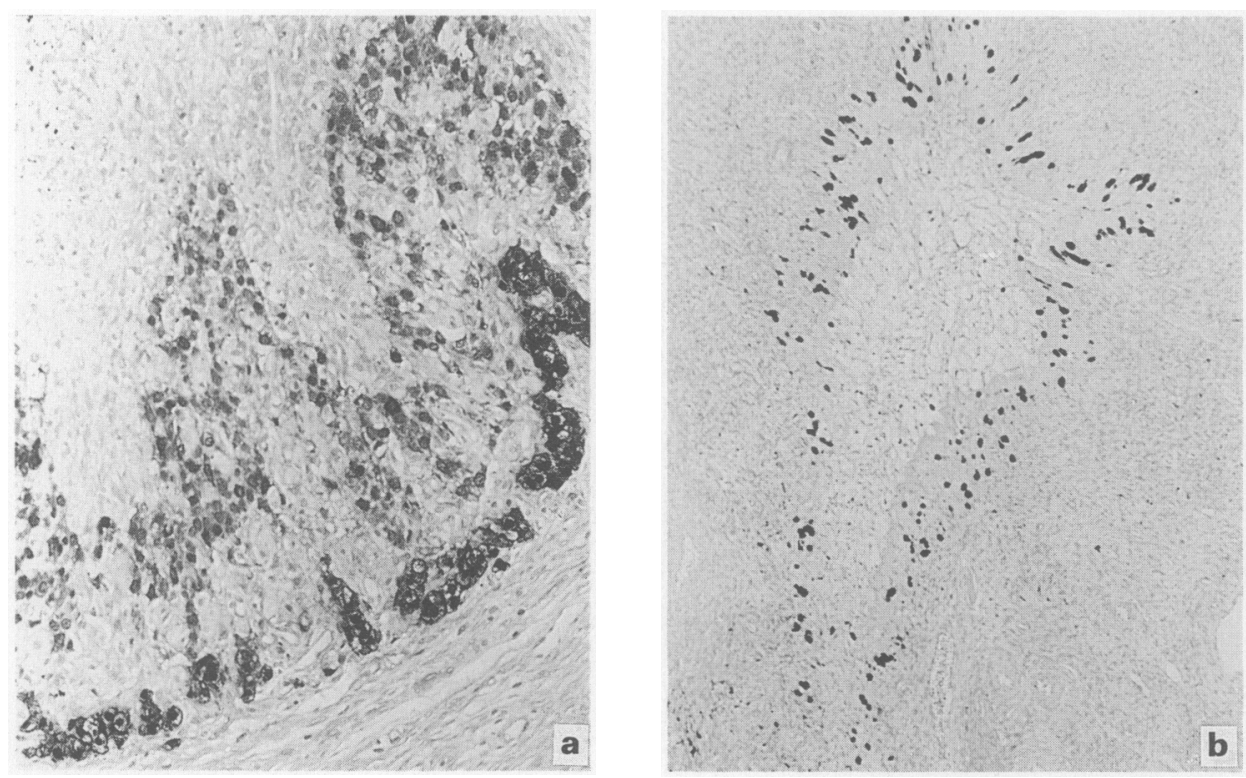

Fig. 6. (a) Day-10 human corpus luteum showing strong nuclear and cytoplasmic staining for glutathione $S$-transferase $\alpha$ with moderate patchy staining of the granulosa lutein layer $(\times 50)$. (b) Persistent strong staining of theca lutein cells in a degenerating human corpus luteum $(\times 50)$.

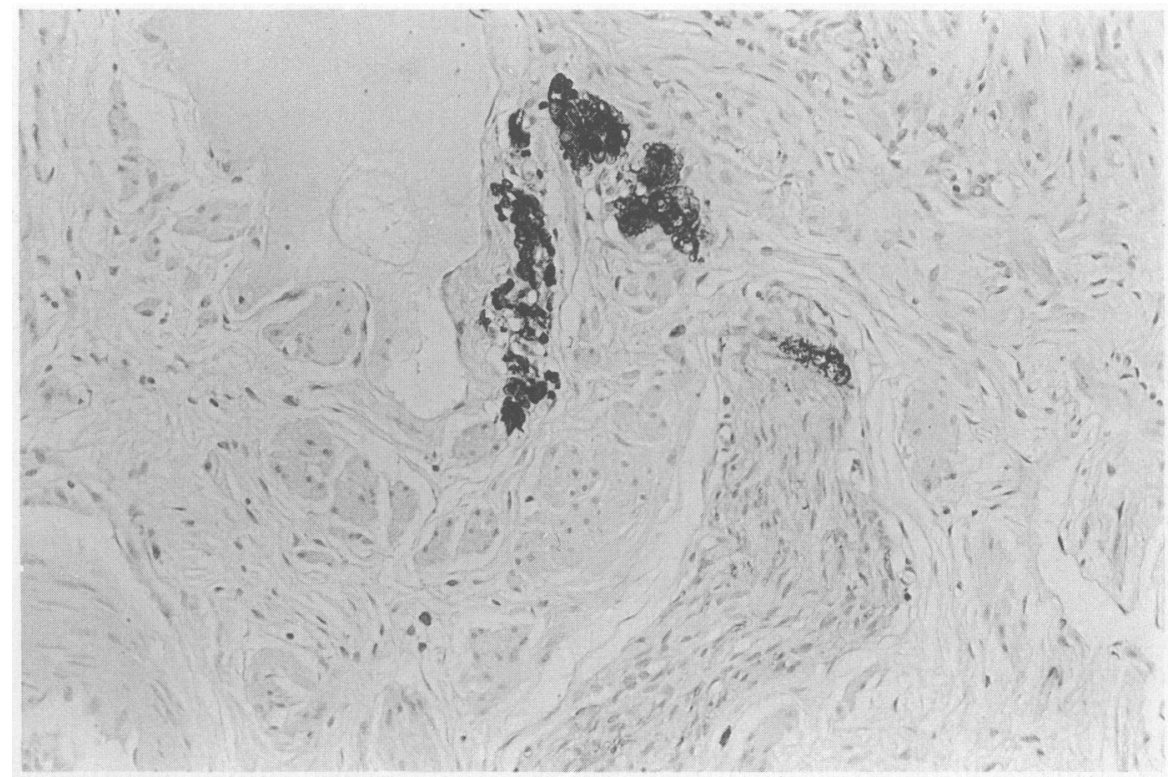

Fig. 7. Clusters of human hilum cells closely associated with nerve fibres, showing intense staining for glutathione $S$-transferase $\alpha(\times 160)$. 


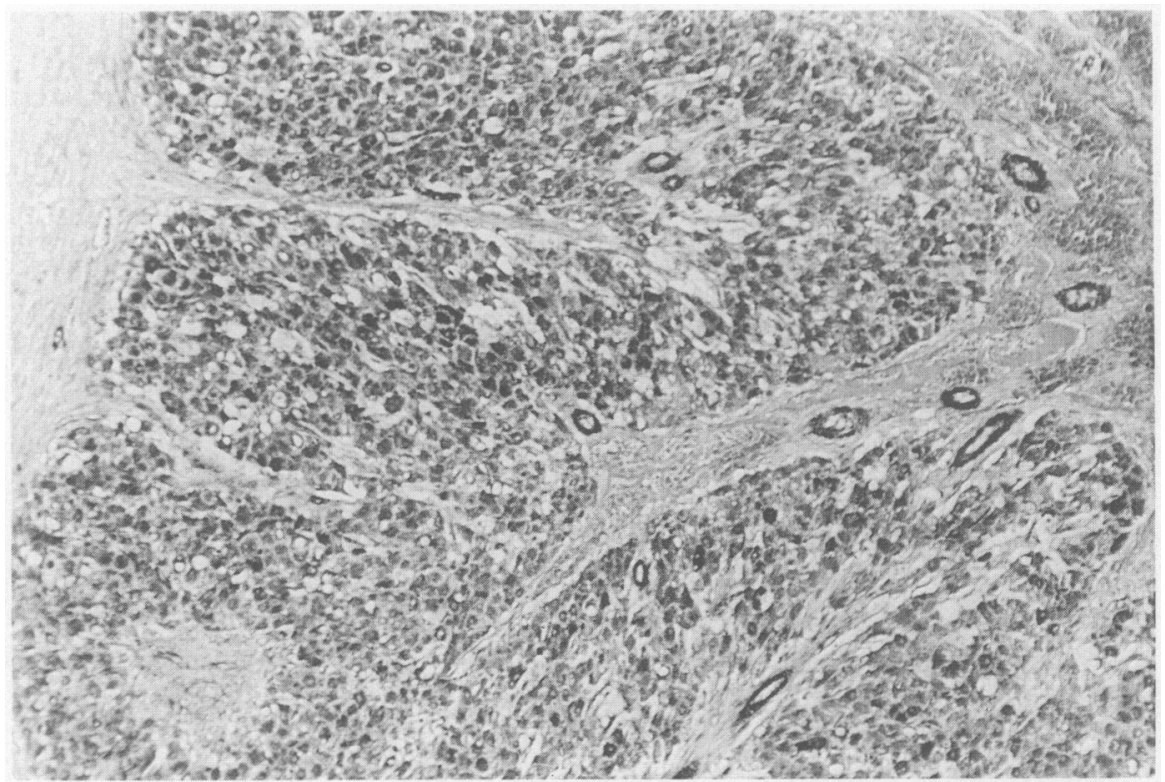

Fig. 8. Cytoplasmic staining for glutathione $S$-transferase $\mu$ in a day-13-human corpus luteum. Note staining of vascular smooth muscle $(\times 50)$.
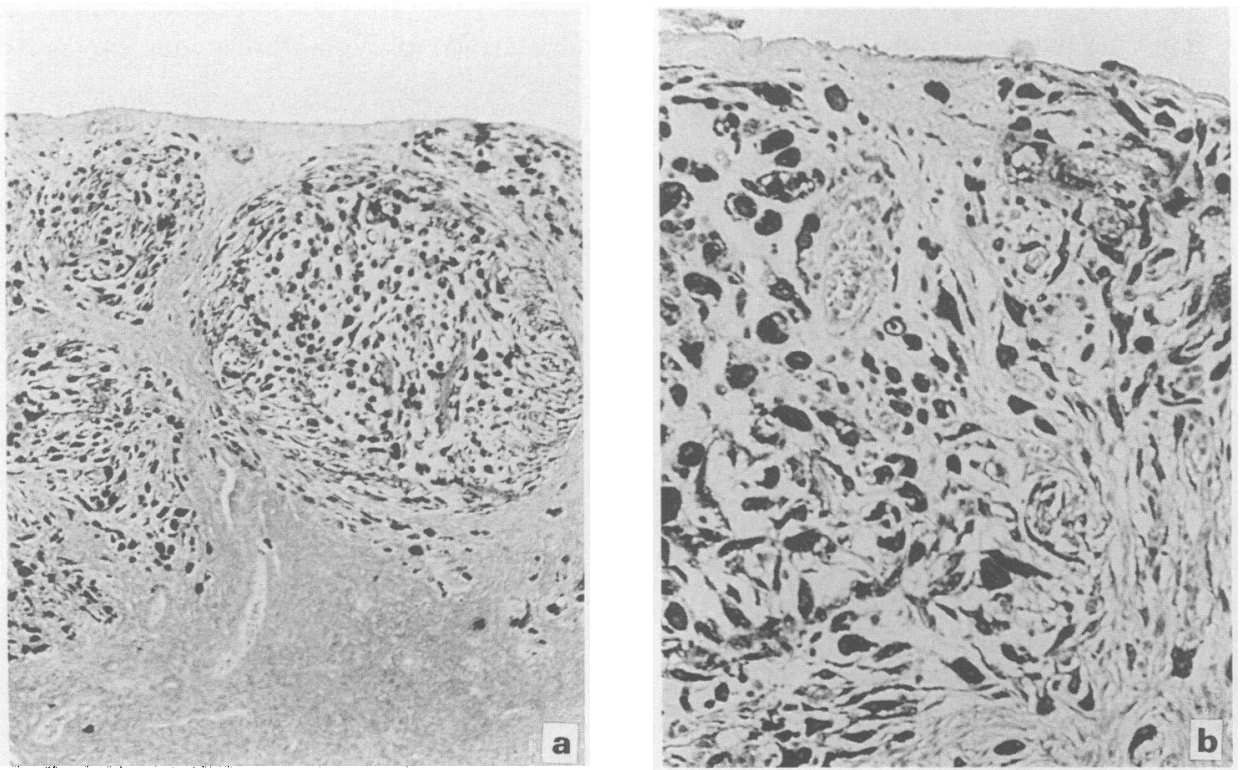

Fig. 9. (a) Human subserosal decidualized nodules showing strong positivity for microsomal glutathione $S$-transferase $(\times 50)$. (b) Higher magnification showing plump decidualized stromal cells $(\times 160)$. 


\section{Discussion}

The presence of GST $\pi$ and $\alpha$ in human ovaries has been documented in a biochemical study (Sherman et al., 1983), but their distribution within this organ is unknown and is probably relevant for their biological function. This study has shown that all four isoenzymes can be identified in normal ovaries and that they are distributed heterogeneously.

The most striking staining pattern was for GST $\alpha$, which was confined to steroid-producing cells, including EASC. A range of oxidative and other types of enzyme activity has been described in EASC (Scully \& Cohen, 1964; Scully, 1979). GST $\alpha$ is closely associated and may have functional identity with glutathione-dependent $\delta$-5,3-ketosteroid isomerase activity (Benson et al., 1977; Warholm et al., 1983). This enzyme, with $3 \beta$-hydroxysteroid dehydrogenase, converts pregnenolone to progesterone. The conversion of dehydroepiandrosterone to androstenedione is accomplished by the same two enzymes. Progesterone production occurs in the granulosa layer (Deane et al., 1962) and commences after a pre-ovulatory surge in luteinizing hormone leads to luteinization of granulosa cells. Its secretion is maintained after ovulation by the granulosa luteal cells. GST $\alpha$ expression in granulosa cells during the second half of the pre-ovulatory phase and in the corpus luteum therefore correlates well with sites of $\delta$-5,3-ketosteroid isomerase activity and supports a role in normal steroidogenesis. Similarly, the presence of GST $\alpha$ in theca interna, luteinized stromal cells, EASC and hilus cells throughout the menstrual cycle can be explained in terms of its association with steroidogenic activity. Numerous in-vitro incubation studies (Rice \& Savard, 1966; Mattingly \& Huang, 1969; Greenblatt et al., 1976) have demonstrated that all these tissues have the capacity to produce androstenedione and hence possess $\delta$-5,3-ketosteroid isomerase. The demonstration of clusters of EASC, which were most numerous in the medullary zone in postmenopausal women, underscores the steroidogenic capacity of ovaries in such women. Another site of androstenedione production is the reticular layer of the adrenal cortex. Campbell et al. (1980) have reported strong positive staining for GST $\alpha$ in cells of the reticular layer, while the glomerular and fascicular layers, as well as the adrenal medulla, were negative.

The reason for the intranuclear location of GST $\alpha$ and $\pi$ is unclear. This has been noted previously in different tissues and does not appear to be solely due to fixation artefact (Hayes et al., 1989). The GSTs may transfer cytoplasmic-bound steroid to high-affinity nuclear receptors (Listowsky et al., 1988).

GST $\mu$, which exhibits genetic polymorphism in liver, kidney and leucocytes, was not expressed in $35 \%$ of the ovaries we studied. This isoenzyme binds a range of steroid hormones including dehydroepiandrosterone and testosterone, but it exhibits high affinity for progesterone (Listowsky et al., 1988). This correlates with the observation that GST $\mu$ was not present in pre-ovulatory follicles, but was expressed in granulosa lutein cells. The regulatory mechanisms involved are not known.

Microsomal GST was not expressed in $70 \%$ of ovaries. Similar variability has been described in the cervix and kidney (Harrison et al., 1989; Carder et al., 1990), but the basis for this is unknown. Microsomal GST showed a similar staining pattern to GST $\mu$ in follicles, with positivity only in granulosa lutein cells. Pregnenolone is converted to progesterone in the smooth endoplasmic reticulum of these cells. The distinct microsomal location suggests that this isoenzyme may be involved in the metabolic conversion of these hormones.

We showed that the four isoenzyme classes of human GST can be identified in the ovary. The heterogeneous distribution described doubtless has functional implications. In particular, the distribution of GST $\alpha$ parallels sites of steroid production and ketosteroid isomerase activity in the ovary and is, therefore, potentially useful in investigating conditions where there is presumed abnormal ovarian steroid production.

We are grateful to J. D. Hayes for the gift of antibodies to GST isoenzymes. The technical assistance of J. Lauder and L. May is gratefully acknowledged. We thank H. Black for typing the manuscript. 


\section{References}

Benson, A.M., Talalay, P., Kee, J.H. \& Jakoby, W.B. (1977) Relationship between the soluble glutathionedependent delta 5,3-ketosteroid isomerase and the glutathione $S$-transferases of the liver. Proc. Natl Acad. Sci. USA 74, 158-162.

Campbell, J.A.H., Bass, N.M. \& Kirsch, R.E. (1980) Immunohistological localization of ligandin in human tissues. Cancer 45, 503-510.

Carder, P.J., Al Nafussi, A., Rahilly, M., Lauder, J. \& Harrison, D.J. (1990) Glutathione $S$-transferase detoxification enzymes in cervical neoplasia. J. Path. 162, 303-308.

Deane, H.W., Lobel, B.L. \& Romney, S.L. (1962) Enzymic histochemistry of normal human ovaries of the menstrual cycle, pregnancy and the early puerperium. Am. J. Obstet. Gynec. 83, 281-294.

Greenblatt, R.B., Colle, M.L. \& Mahesh, V.B. (1976) Ovarian and adrenal steroid production in the postmenopausal woman. Obstet. Gynec. 47, 383-387.

Habig, W.H., Babist, M.J. \& Jakoby, W.B. (1974) Glutathione $S$-transferases: the first enzymatic step in mercapturic acid formation. J. biol. Chem. 249, $7130-7139$.

Harrison, D.J., Kharbanda, R., Cunningham, D.S., McLellan, L.I. \& Hayes, J.D. (1989) Distribution of glutathione $S$-transferase isoenzymes in human kidney: basis for possible markers of renal injury. $J$. clin. Path. 42, 624-628.

Hayes, J.D. \& Mantle, T.J. (1986) Use of immunoblot techniques to discriminate between the glutathione $S$ transferase $\mathrm{Yf}, \mathrm{Yk}, \mathrm{Ya}, \mathrm{Yn} / \mathrm{Yb}$ and $\mathrm{Yc}$ subunits and to study their distribution in extrahepatic tissues. Biochem. J. 233, 779-788.

Hayes J.D., Mclellan, L.I., Stockman, P.K., Chalmers, J. \& Beckett, G.J. (1987) Glutathione $S$-transferases in man: the relationship between rat and human enzymes. Biochem. Soc. Trans, 15, 721-725.

Hayes, P.C., Harrison, D.J., Bouchier, I.A.D., McLellan, L.I. \& Hayes, J.D. (1989) Cytosolic and microsomal glutathione $S$-transferase isoenzymes in normal human liver and intestinal epithelium. Gut 30, 854-859.

Hussey, A.J., Hayes, J.D. \& Beckett, G.J. (1987) The polymorphic expression of neutral glutathione $S$ - transferase in human mononuclear leucocytes as measured by specific radio-immunoassay. Biochem. Pharmac. 36, 4013-4015.

Jakoby, W.B. (1978) The glutathione $S$-transferases: a group of multifunctional detoxification proteins. Adv. Enzymol. Relat. Areas Mol. Biol. 46, 383-414.

Kamisaka, K., Listowsky, I., Gatmaiton, A. \& Arias, I.M. (1975) Interaction of bilirubin and other ligands with ligandin. Biochemistry 14, 2175-2180.

Listowsky, I., Abramovitz, M., Homma, H. \& Niitsu, Y. (1988) Intracellular binding and transport of hormones and xenobiotics by glutathione $S$-transferases. Drug Metab. Rev. 19 (3\&4), 305-318.

Mannervik, B. (1985) The isoenzymes of glutathione S-transferase. Adv. Enzymol. Relat. Areas Mol. Biol. 57, 357-417.

Mattingly, R.F. \& Huang, W.Y. (1969) Steroidogenesis of the menopausal and postmenopausal ovary. Am. J. Obstet. Gynec. 103, 679-693.

Morgenstern, R. \& De Pierre, J.W. (1986) Membranebound glutathione $S$-transferase. Biochem. Soc. Trans. 15, 719-721.

Pabst, M.J., Habig, W.H. \& Jakoby, W.B. (1983) Mercapturic acid formation: the several glutathione $S$-transferases of rat liver. Biochem. biophys. Res. Commun. 53, 1123-1128.

Rice, B.F. \& Savard, K. (1966) Steroid hormone formation in the human ovary. J. clin. Endocr. 26, 593-609.

Scully, R.E. (1979) Tumors of the ovary and maldeveloped gonads. In Atlas of Tumor Pathology, second series, fascicle 16, pp. 16-18. Armed Forces Institute of Pathology, Washington DC.

Scully, R.E. \& Cohen, R.B. (1964) Oxidative-enzyme activity in normal and pathologic human ovaries. Obstet. Gynec. 24, 667-681.

Sherman, M., Titmuss, S. \& Kirsch, R. (1983) Glutathione $S$-transferase in human organs. Biochem. Int. 6, $109-118$.

Warholm, M., Guthenberg, C. \& Mannervik, B. (1983) Molecular and catalytic properties of glutathione transferase $\mu$ from human liver: an enzyme efficiently conjugating epoxides. Biochemistry 22, 3610-3617.

Received 13 August 1990 